\title{
Promoting zero violence from early childhood: a case study on the prevention of aggressive behavior in Cappont Nursery
}

Oriol Rios-Gonzalez, Lidia Puigvert Mallart, Paquita Sanvicén Torné, Adriana Aubert Simón

\begin{abstract}
If aggressive behavior is not interrupted in early childhood the risk of growing up in an environment of continued physical violence increases. Thus, violent behavior can be normalized by certain children who can exert violence without any sense of responsibility. The consequences for children suffering from intimidation and violence by their peers are severe. Previous research shows that to be completely efficient, interventions that target aggressive behavior must begin when children are under the age of five. This study examined how the implementation of evidenced-based actions in Cappont Nursery (Spain), which includes children from 1 to 3 years old, is successfully preventing aggressive behaviors. Data were collected from a qualitative study based on focus groups with adults and observations with children. The results suggest that the most efficient transformative tool to treat aggressive acts is the creation of a zero-violence climate among educators, families and children.
\end{abstract}

Keywords: zero violence, preventive socialization, early childhood, evidence-based, successful educational action 
Relevant studies have shown that if aggressive behavior is not stopped in early childhood and persists during elementary school, the risk of continued physical violence and other nonviolent forms of delinquency increases during adolescence (Williford et al. 2011). Evidence also shows the effectiveness of intervention that targets aggressive behavior when implemented with children under five (Tremblay, Gervais and Petitclerc 2008). The aim of this study is to analyze the violence-prevention actions being implemented in Cappont Nursery, which serves children from one to three years old in Lleida (Spain). This analysis has been realized by collecting the perceptions of educators and family members regarding how the implementation of these actions contributes to prevent violence. This nursery has developed the School as Learning Community project since 2000. The aforementioned preventive strategies are grounded on the Successful Educational Action (SEA, hereinafter) approach, which include evidence-based actions aimed at achieving both social cohesion and educational success. These actions have been identified by the large-scale project INCLUDED, funded by the Sixth Framework Program of Research of the European Union and coordinated by the Community of Research on Excellence for All (CREA) (Flecha 2015). Within these strategies, this article will focus on three of them which are framed on the preventive socialization of violence approach: 1) the dialogic training of educators, 2) effective observation and intervention to overcome attraction to violence and 3) egalitarian dialogue among educators and families to agree to rules implemented in the school. These 
actions are the result of more than 10 years of investigation regarding this issue (Gómez 2015; Flecha, Puigvert and Ríos 2013; Oliver 2014; Puigvert 2014).

The article is divided in three sections. First, we conduct a literature review focused on aggressive behaviors in early childhood and how overcome this violence. Thereafter, we present the research questions and the social context in which the study was implemented, and then we explain the methods used for data collection and analysis. Finally, we present the results and discuss them in relation to previous research.

\section{Aggression in Early Childhood}

In this article, the definition of violence presented in the document "The right of the child to freedom from all forms of violence” elaborated by the United Nations in 2011is considered. This document draws on the article 19 of the Convention on the Rights of the Child which understood violence as "all forms of physical or mental violence, injury or abuse, neglect or negligent treatment, maltreatment or exploitation, including sexual abuse” (UN, 2011, p. 4). In this regard, we will use interchangeably the terms of aggression and violence because they are connected to the physical violence that commonly happen between kids at early ages (Slaby et al. 1995, Walker et al. 2011). In fact, children are directly or indirectly exposed to violence, either as victims or perpetrators at this stage of their life (Finkelhor, Turner, Ormrod and Hamby 2009). Although families want to protect their children from violence, research suggests that it is nearly impossible for children to avoid exposure to any type of violence (Chakraborty, Kumar and Subramaniam 2017). However, there is a false perception about the way children experience violence which is connected with the idea that they are not aware of violence in pre-school. Conversely, the majority of renowned research confirms that any 
exposure to violence at early ages becomes part of children's world vision (Mayes and Cohen 2002).

Data on violence at early ages shows how $70 \%$ of children aged two and three hit other children and 25\% of children aged 17 to 30 months bite other children all the time or occasionally (Tremblay, Japel and Pérusse 1999). Similarly, another study has identified persistent violent practices such as temper tantrums among the most common aggressive behaviors in early childhood and preschool-age children (Daniels, Mandleco and Luthy 2012). Research in this field also stresses attitudes connected to temper tantrums in toddlers and pre-school children that include shouting, screaming, crying, falling to the floor, flailing extremities, hitting, kicking, throwing items, and engaging in breath-holding spells (Eisbach et al. 2014). Nevertheless, other analyses suggest that children's aggressive acts begin to decline after toddlerhood because they learn to control their emotions (Tremblay, Gervais and Petitclerc 2008). However, this social dominance is explained not only by how frequently children attack their classmates but also by how effective and efficient children are in their aggressive behavior (Roseth et al. 2007).

Differing from the research above, the National Survey of Children's Exposure to Violence in Canada (2008) shows that approximately 5 to 10\% of children maintain highly aggressive behavior even when they have grown and are no longer in preschool. Children who do not learn from an early age to replace their physical aggression with a more socially appropriate behavior are at considerable risk to face school difficulties, delinquent and criminal behaviors, substance abuse problems, and unemployment (Tremblay, Gervais and Petitclerc 2008). Likewise, other investigations have indicated the negative effects in early adolescence of not overcoming disruptive behaviors in the preschool years, particularly with regard to in a youth’s social and emotional skills (Niles et al. 2014). 


\section{Effective Observation and Intervention to Prevent and Stop Aggressive Acts}

A number of studies provide useful data for preventing and stopping aggressive acts among peers and for creating a peaceful environment (Cameron et al. 2008; Hart and Ostrov 2013; Howes et al. 2011; Kragh-Müller 2011; Ostrov 2009; Slaby et al. 1995; Kiuru, et al. 2012; Vallotton and Ayoud, 2011; Williams, et al. 2010; Redondo 2016). Nevertheless, certain professionals and families still support pedagogical approaches that tolerate and naturalize aggressive behaviors (Oliver 2014). Contrarily to these approaches’ lack of robust evidence, other research, underpinned by rigorous scientific analyses, underscores the necessity of putting in practice evidence-based interventions (Ostrov et al. 2009). One recognized action to prevent aggressive behavior is effective observation and intervention (Aiello, Puigvert and Schubert 2018; Puigvert, 2014; Vidu, Valls, Puigvert, Melgar and Joanpere 2017; Valls, Puigvert, Melgar and García-Yeste 2016). Research confirms that efficient observation requires that early childhood educators know what is occurring in their classroom. In this regard, it is crucial to observe what occurs before, during, and after an aggressive act. This means educators must correctly identify the aggressors and victims to know exactly what type of aggressive behavior occurred.

For instance, taking action when aggressive act occurs among children becomes a preventive mechanism against further aggression (Mayes and Cohen, 2002; Slaby, et al. 1995). This strategy is implemented by standing between harassers and victims, giving attention to the latter and ignoring the former. Another effective intervention in addressing conflicts is teachers' reinforcement of peers' capacity for dialogue. Thus, studies underline how important is that early childhood educators encourage children to use their words to solve conflicts with peers (Vallotton and Ayoub 2011). 
Along these lines, research underscores the role of educators in facilitating the setting of peaceful classrooms in early childhood. Certain studies stress how important is that educators and relatives not to minimize aggressive behaviors by considering them "kids' stuff” (Duque et al. 2015). The intervention of educators helps create safer classrooms and protects children's rights. Educators may also encourage other children to support the victim and move away from a violent scene (Slaby et al. 1995). This safer atmosphere in the classroom is consolidated when educators promote positive interactions among peers (Howes et al. 2011). In summary, research provides significant evidence that permanent and efficient observation-intervention and close and supportive teacher-child relationships during the preschool years contributes to construct positive relationships (Howes et al. 2011; KraghMüller and Isbell 2011; Kiuru, et al. 2012; Sutherland et al. 2018). Drawing on this premise, staff, and parents involved in the nurseries, develop a proactive role as bystanders, observing, identifying, stopping and preventing violent interactions among children (Lambe, Hudson, Craig and Pepler 2017; Oliver, Soler and Flecha 2009; Polanin, Espelage and Pigott 2012; Salmivalli 2014; Urra-Canales, Acosta-Oidor, Salazar-Baena and Jaime-Ruiz 2018).

\section{Preventive Socialization of Violence: Overcoming Attraction to Violence from Early Childhood}

Despite efforts to prevent school violence, children who are aggressive towards others attract the attention of their peers and teachers (Valls, Puigvert and Duque 2008). This trait is strongly connected with their capacity to establish dependent relationships; in fact, the majority of their peers are attracted by these children's power, which provides them with a social circle (Mayes and Cohen 2002). Similarly, other studies provide evidence that certain 
aggressive children enjoy a high social status, particularly if the group is supportive or neutral regarding aggressive behaviors (Boivin, Vitaro and Poulin 2005).

Relevant evidence has been collected to provide social responses to violence in school that differ from previous analyses. For more than a decade, exhaustive field work has been conducted in primary and secondary education to examine the link between attraction and violence (Gómez 2015; Flecha, Puigvert and Ríos 2013; Racionero, Ugalde, Puigvert and Aiello 2018; Valls, Puigvert and Duque 2008). The results confirm the existence of a type of socialization that generates an attraction toward violence (Gómez 2015). This socialization process begins with the first interactions at early ages, when aggressors who dominate others are considered attractive (Valls, Puigvert and Duque 2008). Thus, peer- to-peer interactions become crucial in shaping children's behavior. In fact, studies on preventive socialization suggest that children who are more violent and aggressive are the most valued. Thus, to overcome the attraction towards violence, it is also crucial to foster safe environments where children do not hit others at early ages. However, the valorization of these children using only the language of ethics with sentences such as "these children are good boys" is not enough to overcome this situation. Rather, it is more effective to use the language of desire by employing statements such as "those who do not hit are brave boys" (Flecha, Puigvert and Ríos 2013).

\section{Methods}

\section{The Study Context}

Cappont Nursery, a municipal nursery for children one to three years old, is located in the neighborhood of Cappont in Lleida, Spain. During the 2014-2015 school year, 52 children were enrolled in the Nursery. Cappont, the only nursery in the neighborhood, has a very diverse population, including students from families with a low SES and from a minority 
background. Since its transformation into a Learning Community, Cappont has achieved multiple awards, including the Evens Prize for Peace Education in 2015. This biannual prize recognizes initiatives and practices that strive to awaken and strengthen the social competence of preschool children with particular focus on skills that facilitate a constructive attitude towards conflict (Evens Foundation 2015).

Because birth to three years is considered a non-compulsory educational stage in Spain, there are no external evaluations or numerical outcomes that measure children's social, emotional and cognitive development. Therefore, it is not possible to compare the improvement of Cappont Nursery to other nurseries with similar backgrounds. Nevertheless, the school has fulfilled relevant criteria by implementing SEAs (Flecha 2015) since 20002001, when the process of turning the school into a Learning Community began. Schools as Learning Communities is a project based on SEAs aimed at achieving social cohesion and educational success. This educational model is consistent with international scientific theories emphasizing two elements that improve education: interaction and community involvement (García-Carrión and Díez-Palomar 2015; Bruner 1985). Notably, the INCLUD-ED project defines SEAs as actions that obtain the best results regardless of the context in which they are implemented (Flecha 2015).

\section{Research Questions \& Data Collection}

This study answers two main research questions: what preventative actions addressing aggressive acts are being implemented in Cappont Nursery? What perceptions do educators and families have regarding the impact of preventative actions in the consolidation of a zeroviolence atmosphere? To address these questions, two different qualitative instruments were implemented: focus groups for educators and relatives and observations for children. 
Both instruments are based on the communicative methodological approach which is characterized primarily by questioning the traditional hierarchy between researchers and researched subjects. Thus, communicative methodology begins with the premise that scientific knowledge is constructed from an egalitarian dialogue among actors involved in the research process (Gómez, Puigvert and Flecha 2011). Particularly, in relation to the communicative-oriented focus groups, these are natural groups based on the shaping of an atmosphere of trust and dialogue. Obviously, a researcher contributes his/her academic knowledge, but the interpretations come from consensus among all participants.

The selection criteria for being part of the sample was based on being an adult and entering inside the classrooms to observe children's interactions and help them with their learning. Therefore, in the study participated 6 educators ( 5 women and 1 men) and 10 mothers who were regularly observing children's behaviors. The years of experience of educators in the school go from twenty to six years. To contact with these subjects, the research team talked directly with the principal of the school in order to organize the focus groups. This contact helped to design the composition of the focus groups. Then, the principal suggested us to organize different sessions to deepen on the interventions carried out to prevent violence. Finally, three focus groups with educators and two with a mixture of educators and mothers were organized. In these mixed focus groups, the aforementioned diversity of the families was guaranteed. The following table depicts the setup of each focus groups.

The other instrument, communicative-oriented observation, has been performed in different periods of the school's transformation to a Learning Community. Thus, researchers have observed and followed up on successful strategies conducted at the school regarding the zeroviolence approach, aiming to identify how interactions and dialogues among members of the 
community, particularly children, were being shaped to reduce aggressive behavior. These observations have been conducted in the different age stages of the school: from 0 to 1 years old, from 1 to 2 years old and from 2 to 3 years old.

\section{Data Analysis}

Data from the focus groups were transcribed verbatim and field notes from the observations were collected. Both instruments were analyzed following the principles of communicative methodology, meaning that exclusionary and transformative dimensions were differentiated. Thus, the first dimensions refer to barriers that hinder the creation of a zero-violence atmosphere. Conversely, the second dimension concerns attitudes and practices that enable SEAs in the prevention of violence.

\section{Results}

\section{Dialogic Training of Educators}

Scientific literature confirms that schools whose staff is trained intensively on evidence-based actions become more efficient in the prevention of aggressive behavior from early childhood (Girard et al. 2011; Hart and Ostrov 2013; Pianta et al. 2014). In this regard, Cappont Nursery considers staff training on SEAs as essential. Thus, in the next quote the principal of the nursery highlights the impact that this training has achieved in strengthening professional development.

We work a lot on the professionalism, getting trained, always questioning about our performance with a clear aim: to improve. It takes time because we have the need to permanently discuss and argue, as well as to reflect about what we do. 
One practice performed within this training includes dialogic pedagogical gatherings (DPG) (Roca, Gomez and Burgués 2015) where scientific books and articles are discussed establishing a rigorous dialogue about the evidence presented in the texts. Thus, no one acts as an expert because in DPG the relevance is given to people's arguments that should be connected with evidence. In these discussions, collective knowledge is created to address preventative actions towards violence in early childhood. Meanwhile, the identification of aggressive acts in children is not left to staff members' thoughts and perceptions, because this process is always based on knowledge accumulated in DPG.

The principal provides reflections linked to this change. In the past, she often understood children's behavior that made other children cry as “kids' stuff”. However, after Cappont's staff began to train themselves on SEAs, they began to identify aggressive behaviors as a part of interaction with another person as it can be observed in the next quote (Girard et al. 2011).

I have indeed changed my own perception about what is violence or aggressive behaviour. If any child did so, I did not consider it as a violent act even though he/she was disturbing another child. But now, I do regard it as a violent act since now I regard as violence any single act that offends another person who evidently dislikes it.

\section{Permanent Scientific Dialogue among Educators and Staff}

Another action that makes a difference in this preventive effort is the continuous dialogue and reflection of the staff regarding their practices. This process enables a dialogic recreation of knowledge, means that the strategies implemented are continuously debated in the 
community (Oliver 2014). Since Cappont Nursery began to implement SEAs, the staff members have weekly meetings to establish common actions. However, any issue can be discussed without waiting for this coordinated meeting, because staff also addresses issues during their lunch time as it is expressed by one of the educators of the school:

We have time to lunch and talk between 12:00 and 13:30 hours. The topics under discussion are dealt with daily when they appear; we do not wait for the weekly meeting. We explain to each other when one of us is asked for a meeting with families. Therefore, we discuss the topic prior to the meeting and then we talk about the results.

Another educator's words exemplify how validity claims are normally employed in these dialogic spaces, in which it is possible to modify the strategies to be followed through the discussion about SEAs.

All of us change our way of thinking based on what we discuss among ourselves. At the beginning I could have my own view, but after discussing with my colleagues, I could modify my views. Things go very well when all of us reach a consensus.

Normally, there are not established criteria regarding coexistence to fulfill in the schools; however, Cappont Nursery encourages an ongoing dialogue to agree on messages and responses provided to children. Therefore, Cappont's staff adopts SEAs grounded in scientific evidence to fulfill this objective and establish common rules (Denham and Weissberg 2004). Each educator provides identical messages that are clear. This is how an educator describes this procedure: 
Clarity, rigor, forcefulness and coherence: always the same response when facing identical situations. It equally applies for all teachers. Even though there are no written protocols, there are agreed pacts among all of us about the best way to deal with conflicts and aggressions.

This consensus on acting identically enables children to work together in a common space. Thus, there is a very large common space that is open to all the classrooms, allowing children of different ages to share activities at the same time. An educator emphasizes that this space is possible because they follow the same intervention criteria.

Working under an open doors environment is only feasible because there is coordination, coherence, involvement, dialogue and mutual trust. If these items were not there, then it would not be possible to work in an open space; it would end in chaos, and aggressiveness would arise (...) and these facts make the children to be confused and with negative thoughts.

Considering an educator's words, this coherence generates self-confidence in children and a peaceful atmosphere at lunch time; no one yells or cries, and it becomes a situation free of violence:

The norms are very simple: no yelling, respect children, behave in a coherent way. If you ask a child if he/she wants soup, the child could reply either yes or no. If the answer is no, you won't give soup. Thus, children feel secure as they know which rules are to be applied in all cases.

\section{Effective Observation and Intervention to Overcome Attraction to Violence}


Another important norm to achieve zero violence is the performing of effective observation without children noticing. This type of observation allows staff to stay ahead of conflict. The fact that educators work in the same common open space with the same attitude ensures that everybody remains alert. In addition, their continuous dialogue allows them to know all the children and their ways of performing. For example, if a girl exhibits a poor behavior by hitting other children, her behavior is discussed within the team, as it is confirmed by an educator:

I tell my colleague: "I turn over, please keep an eye on her - speaking quietly to her about a little girl that reacted by hitting her class mates - as we are aware that this is a case that has to be under control for being repetitive. During three or four days (this girl) did not have any chance to hit anybody, as each time she made the gesture, we said something to her. This attitude ended very quickly.

This strong understanding among educators and staff regarding effective observation makes it possible to create a safe situation at the school. As one educator notes, "The main idea, which I do love, is to create safe situations at the school.” Acting together to prevent any type of situation that may cause conflict helps to create an atmosphere of zero violence. In addition, the staff has agreed on ways of acting that erase the attractiveness of aggressive acts or transgressions from an agreed norm. Notably, these alternative activities become attractive because educators intervene when any violent behavior is reproduced; in fact, educators look for ways to end aggression. In this regard, as an educator affirmed, it is useful to intervene immediately once a violent game begins because and present children alternative activities that are attractive to them. 
Sometimes we could face a violent game in which children are faking a fight. If the fight implies two boys against one, educators are relentless from the start, even if it looks like a game it quickly turns into being real. Relentless means that we stop the game and we propose to them another interesting activity.

This attractiveness is an issue that is always considered in the staff's professional development as presented in the next quote. Thus, the concept is integrated not only when educators design games but also when they supervise children's daily interactions. In this way, children who are abusive quickly learn that this attitude is not an effective way to attract the attention.

What we are after is that the boy or girl who plays like that, that is, violent or imposing who can and who cannot participate in the games, has to realize that his behavior is no good in attracting our attention, or at least does not foster it.

However, not paying explicit attention to children who behave aggressively or dominantly towards other classmates does not mean that educators are passive with these children. For example, one effective intervention in this regard is quietly approaching children when they are behaving badly and talking to them in low voice. Another member of Cappont's staff reported the effectiveness of this intervention based on the premise of removing the protagonism and attractiveness of conflictive behaviors:

Not giving him protagonism, you go there and spontaneously you tell him: "No, come on, get down, we cannot play on the table." That's it. Because if we raise our voice 
and we say loudly "no, don't do that", then for sure we have a problem. If someone wants to draw attention on him, he knows what to do next time.

When a more alarming situation arises, such as physical aggression, the effective intervention is to give full attention to the victim and not to the aggressor. Through this intervention, the victim is supported and his or her back is placed toward the aggressor. One educator confirms that taking care of the victim also implies watching the aggressor but without giving him/her more importance.

You put your back to the aggressor, you take the hit child, caring for him/her, and making sure the aggressor does not know you are watching him/her. But the aggressor sees that you are giving protection to the victim. So, you give affection to a child and at the same time you keep watching the other without him/her noticing.

Another educator agreement to remove the attractiveness of aggressive behavior includes not obliging them and the aggressor to kiss each other. In fact, this is practice has become widely normalized in Spain. However, when an aggressive act occurs at Cappont Nursery, educators always attempt to downplay the attractiveness of an act, and therefore do not force the victim to kiss the classmate.

\section{Continuous and Egalitarian Dialogue with Children and their Families}

Apart from the actions previously mentioned, Cappont Nursery also encourages dialogue between educators, families and children to prevent aggressive acts. With regard to dialogue between children and educators, Cappont underscores the following five elements: 1) to teach children to use words to express their feelings; 2) to reflect reasons for the statement "cannot 
be done"; 3) to teach children the meaning of "no means no"; 4) to speak with children about the relevance of not labeling anyone; and 5) to use a type of language that fully respects children. Firstly, staff members teach children to use words to describe their feelings. As one educator explains, this effort helps to empower children and reinforce their self-esteem which are crucial factors in preventing aggressive behaviors.

Not knowing how to argue and how to explain things generates frustration and insecurity, in short, making them weaker (...). Teaching the children to explain what they think, what happens to them, what their feelings are, helping them out with words is a way to empower them and to make them feel self-confident.

Concerning the statement "cannot be done," research illustrates that the permanent dialogue that staff establishes with children is useful in consolidating the fulfillment of the coexistence rules. For example, when a child takes away a toy from another child, educators tell children that they cannot take the toy because someone does not like that action. One female educator explains this strategy, emphasizing the fact that children learn the meaning of "no" within daily interactions.

When a child pinches a toy from another then we do not consider it as something natural, nor acceptable. We work on the "no” contextualized: “Don't pinch it, can't you see that he/she was playing with it? He/she does not want you to pinch it." And we say to the other child: "You have to tell him that you do not want him to take the toy from you as you are playing with it now. You can give it to him later when you finish." 
With regard to labeling, educators confirm that the dialogue established with children is grounded in an absolute respect towards them and a rejection of labels for children. The staff focuses, as it is evidenced on the next quote, its intervention on the possibility of transforming conflictive behavior into non-aggressive behavior, rather than on stigmatizing minors. As previously discussed, when aggressiveness does not attract attention, children radically change.

Many times we see (that the aggressive act) is due to the fact that the child has not had yet any other manner to relate, nor express his/her feelings for what has lived so far, because it has been what managed to attract full attention on him/her.

The final element to emerge from field work involves the importance of educators’ language. Several interviewees affirmed the effectiveness of employing clear and elaborated language that avoids sounding childish. Educators treat children as fully human beings, avoiding the use of diminutives and guaranteeing that clarity is the basis of their messages. For instance, one educator said that if a child hits the arm of someone else, they do not tell him/her, “Don’t hit him/her; you have hurt his/her little arm”. Instead, they say, "You have hurt his/her arm”.

As mentioned above, dialogue with children's families is also fundamental in achieving consensus about actions to be taken. For example, one mother involved in the focus groups explained how families feel that norms and actions implemented in the center are agreeable to them: 
The nursery is not somewhere where what educators say gets immediately implemented because they say so and that's it (...) but on the contrary, rules are jointly established by all parties concerned.

This consensus at Cappont Nursery creates a mutual trust that presents opportunities for families, making them feel comfortable about requesting or commenting to the staff about an issue or concern. This trust is explained separately by one educator and one mother:

The idea is to be respectful to what families have to say, calm them down, remove their anxiety, tell them "we shall have a proper look, we shall watch it, we shall keep you posted". We ask them as well "to keep on asking us about any topic as perhaps I may forget to inform you, so please feel free to ask us. (Educator)

Whenever I worried about something concerning my son, I have addressed the educators and asked them: How should I do it? What do you think? Am I doing it right? They offered me a solution all the times. (Mother)

To sum up, findings presented in this section illustrate the relevance of two key elements for the prevention of violence at early ages. One of these elements is educators' role which is very relevant when they promote a scientific dialogue in the school as well as they participate in training activities framed on evidence-based educational actions. The second element is related to the implementation of dialogic interventions which involve families and children in the design of school rules. In other words, violence prevention at early ages occurs when spaces of dialogue are opened to the whole community to decide about coexistence issues. This summary is explicitly detailed in Figure 1. 


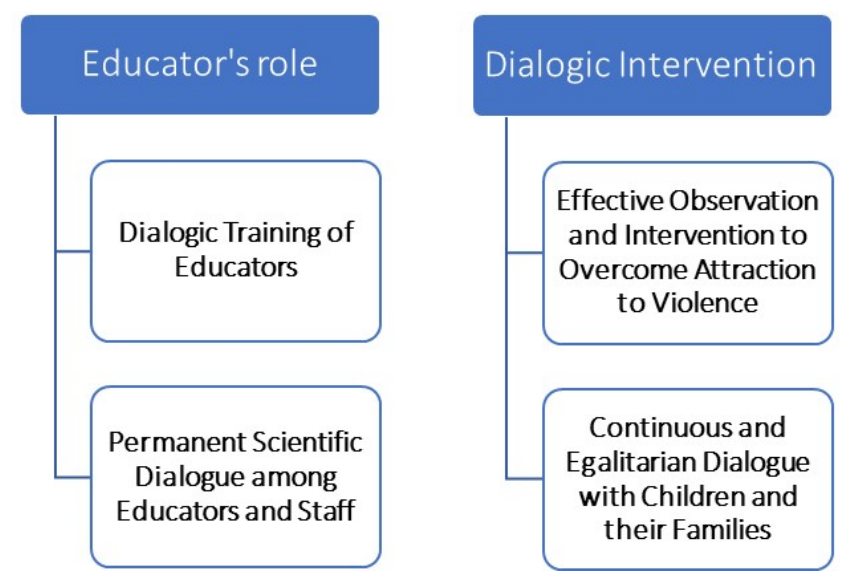

Figure 1. Results Diagram

\section{Discussion}

The fulfillment of a zero-violence climate in Cappont Nursery is reached through two specific strategies the implementation of SEAs such as the dialogic training of educators and an effective observation and intervention to overcome attraction to violence, and a permanent dialogue with families about the interventions to perform. Previous studies have analyzed how this dialogic approach has helped to prevent violence in primary schools, high schools and universities (Vidu at al. 2014; Hart and Ostrov 2013; Howes et al. 2011; Kragh-Müller 2011). However, there is a lack of studies that analyze the impact of these elements on the creation of a zero-violence climate in an early childhood center. Therefore, this analysis covers an important gap in this regard.

Notably, the dialogic training conducted at Cappont Nursery shows the effectiveness of designing teacher training based on successful, evidence-based actions to prevent aggressive behaviors in early childhood. This dialogic approach encourages educators to collectively create useful knowledge. Thus, this training opens areas of debate about the benefits of creating a close educator-child relationship (Howes et al. 2011) and improving 
children's use of socially acceptable behavior (Girard et al. 2011). Additionally, dialogic training facilitates improvements in professional skills linked to the prevention of aggressive acts in early childhood. One of these skills concerns effective observation and intervention to address aggressive behavior (Tremblay, Gervais and Petitclerc 2008).

The second element emphasized in our field work is the importance of sharing knowledge with families on an egalitarian level. In Cappont Nursery, dialogue with families is continuous and egalitarian. Hence, staff members do not consider themselves as experts; instead, they listen to families' concerns in a climate of confidence and collectively find strategies to solve them. Thirdly, Cappont Nursery creates an atmosphere based on zero violence and framed using the preventive socialization approach, which is crucial for removing children's attraction to violence. Previous studies have shown evidence that children who have a dominant role at the nursery draw the attention of both teachers and peers (Hawley 2007). Nevertheless, this study illustrates how Cappont Nursery is changing this dynamic by reducing the attraction toward violent behavior. If aggression occurs between two children, the educator intervenes by focusing her/his attention upon the victim and ignoring the aggressor.

Finally, we would like to mention certain limitations in our investigation and recommend further steps to be considered in this field. One of the most important limitations concerns the young ages of the subjects analyzed, which made it difficult to collect children's reflections about coexistence in the nursery. Another limitation relates to the existing confusion in educational approaches regarding what constitutes violent behavior in these early ages. A further limitation is the lack of indicators which quantify the improvement of coexistence in nurseries. 